\title{
Survey
}

\section{E Do Pain Medicine Fellowship Programs Provide Education in Practice Management? A Survey of Pain Medicine Fellowship Programs}

Rene Przkora, MD, PhD ${ }^{1}$, Ajay Antony, MD¹, Andrew McNeil, DO ${ }^{1}$, Gary J. Brenner, MD, PhD², James Mesrobian, $\mathrm{MD}^{3}$, Richard Rosenquist, $\mathrm{MD}^{4}$, and Amr E. Abouleish, MD

From: ${ }^{1}$ Department of Anesthesiology, University of Florida College of Medicine, Gainesville, FL; ${ }^{2}$ Massachusetts General Hospital Pain Center, Boston, MA; ${ }^{3}$ Team Health Anesthesia, Milwaukee, Wl; 4Department of Anesthesiology, Cleveland Clinic, Cleveland, $\mathrm{OH}$; 5Department of Anesthesiology, University of Texas Medical Branch, Galveston, TX

Address Correspondence: Rene Przkora, MD, PhD Department of Anesthesiology, University of Florida College of Medicine PO Box 100254 Gainesville, FL 32610

E-mail: rprzkora@anest.ufl.edu

Disclaimer: This study is supported by the American Society of Anesthesiologists Committee on Practice Management, Chair: James R. Mesrobian, MD. It received Level 1 funding.

Conflict of interest: James

Mesrobian, MD, is Chair of the American Society of Anesthesiologists Committee on Practice Management. All other authors report no conflicts of interest.

Manuscript received: 03-16-2017

Accepted for publication: 08-11-2017

Free full manuscript: www.painphysicianjournal.com
Background: We hypothesized that there is a gap between expectations and actual training in practice management for pain medicine fellows. Our impression is that many fellowships rely on residency training to provide exposure to business education. Unfortunately, pain management and anesthesiology business education are very different, as the practice settings are largely officeversus hospital-based, respectively.

Objective: Because it is unclear whether pain management fellowships are providing practice management education and, if they do, whether the topics covered match the expectations of their fellows, we surveyed pain medicine program directors and fellows regarding their expectations and training in business management.

\section{Study Design: A survey.}

Setting: Academic pain medicine fellowship programs.

Methods: After an exemption was obtained from the University of Texas Medical Branch Institutional Review Board (\#13-030), an email survey was sent to members of the Association of Pain Program Directors to be forwarded to their fellows. Directors were contacted 3 times to maximize the response rate. The anonymous survey for fellows contained 21 questions (questions are shown in the results).

Results: Fifty-nine of 84 program directors responded and forwarded the survey to their fellows. Sixty fellows responded, with 56 answering the survey questions.

Limitations: The responder rate is a limitation, although similar rates have been reported in similar studies.

Conclusions: The majority of pain medicine fellows receive some practice management training, mainly on billing documentation and preauthorization processes, while most do not receive business education (e.g., human resources, contracts, accounting/financial reports). More than $70 \%$ of fellows reported that they receive more business education from industry than from their fellowships, a result that may raise concerns about the independence of our future physicians from the industry. Our findings support the need for enhanced and structured business education during pain fellowship.

Key words: Business education, practice management, fellowship training, curriculum development, knowledge gaps, private practice

Pain Physician 2018; 21:E43-E48 
W hen embarking on a one-year Accreditation Council for Graduate Medical Education (ACGME) accredited pain medicine fellowship, a trainee must obtain an abundance of knowledge and skills in a relatively short time. Whether the trainee's background is in anesthesiology, physical medicine and rehabilitation, neurology, psychiatry, or any other specialty, he or she is likely to have large knowledge gaps regarding pain medicine given the variation in exposure to the field during residency. In addition, procedural skills that are fundamental to the practice of pain medicine must be developed and refined over the course of the fellowship. Pain medicine fellows expect to achieve these metrics, and the minimums for procedural exposure are clearly defined by the ACGME. All programs evaluate their trainees' clinical skills prior to graduation, and because the standards of procedural and clinical competency often vary from program to program, some have suggested that defining a baseline standard of evaluation and assessment would be of great value (1).

In addition to the clinical skills taught during the pain medicine fellowship, the business side of pain medicine, such as practice management, is a key element for the trainee to learn and be a part of the expected curriculum before he or she graduates. It may be that faculty at training programs have had formal training in practice management. The majority of graduates will embark on a career in private practice, and this knowledge is relevant not only in the long term to their future career, but in the short term as they go out to interview and need to assess the business acumen of the practice prior to making a decision regarding where to work. There is also great variation as to what aspects of practice management will be important for the individual trainee, based on many factors (2). Other postgraduate training programs have shown that improvement in business intelligence can be greatly enhanced with adequate mentorship and education $(3,4)$. As the majority of pain medicine fellowship graduates move on to a private practice business model as a career choice (for example, $75 \%$ to $100 \%$ of the fellows at the University of Florida), the importance of practice management education cannot be overlooked. Ultimately, sound practice management knowledge will maintain the viability of our speciality and will facilitate our patients' access to care. We hypothesized that there is a significant gap in the expectations versus the actual training of pain medicine fellows in business and practice management during their fellowship.

\section{Methods}

Prior to data collection, a 21-question survey and planned study methods were sent to the University of Texas Medical Branch Institutional Review Board, which declared that written informed consent was not required. In the survey, which was drafted by a physician MBA, pain medicine physicians in both academics and private practice, and pain medicine fellows, assessed the presence or absence of formal practice management education in ACGME-approved pain medicine fellowship programs across the United States. To our knowledge, it was the first of its kind in pain medicine, and no validation tool was available. Email contacts of fellowship program directors were obtained using the database of the Association of Pain Program Directors. The survey was then forwarded to the fellows of the respective programs at the discretion of the program directors. The email survey was sent 3 times between March and June 2013. The survey itself began with a binary question for the fellowship program directors asking if there is a presence or absence of practice management education within the fellowship program. Despite the inherent limitations of a binary question, we felt it was necessary to establish a baseline presence or absence of practice management education within the program. The survey specified that this education had to be more than anecdotal or "on-the-job" training; that preferably, formal didactic sessions took place and there was protected time for this learning to occur. If the program director answered "yes" to this initial screening question, additional questions were asked in the survey to be answered by the fellows. Each of these questions focused on specific aspects of practice management, eliciting a "yes" or "no" response. The topics for each question are listed below:

- Billing documentation/compliance

- Charges/revenue

- Physician versus facility revenues

- Precertification/authorization

- Monthly financial reports for practice

- Contracts with payers

- Employee contracts

- Human resource topics (as the employer)

- Job search (CV writing, interviewing)

- Future healthcare options 
Another question posed in the survey concerned the role of practice management training from industry/ company-sponsored courses that many fellows attend. The final question of the survey quantified the number of contact hours spent in practice management in increments of 1 to 4,5 to 9 , and 10 or more hours.

\section{Results}

Of the 84 program directors from ACGMEaccredited pain medicine fellowship programs that were forwarded the survey for fellow completion, 59 responded, constituting a $70 \%$ response rate. Of these, 44 indicated that their program provided some form of practice management education, whereas 15 stated they did not offer any formal training. The program directors then forwarded the survey to their fellows. In total, 60 fellows responded and 4 fellow surveys were excluded due to incomplete or invalid entry; thus, $93 \%$ of the total surveys received were complete and fully analyzed for this study. A complete summary of the data recovered from the 56 usable fellow surveys, including all 21 questions with percent response, can be found in Table 1.

The survey results also indicate that the most common length of time spent in formal education for practice management was 1 to 4 hours (64\%), with only $7 \%$ of programs offering greater than 10 hours of formal education during the fellowship year (Fig. 1).

Finally, the participants were surveyed regarding who provided more education on practice management: their institution or outside/private companies. Seventy-one percent of those surveyed indicated they received more education about practice management from outside/private companies than from their institution/fellowship program.

\section{Discussion}

During a residency training program, trainees are generally exposed to business and practice management aspects of their respective fields. Because pain medicine fellows come from several different training backgrounds, their exposure is highly variable. In addition, within a given primary specialty, there are large differences in practice management exposure and education. Core residency programs as well as pain medicine fellowship programs vary greatly in size, patient population, and clinical exposure. The background knowledge in business and practice management of incoming pain medicine fellows is distinctly different based on a number of factors (1).
Another feature highlighting the need for business education by pain medicine fellowships concerns differences between the business of pain management and that of other medical disciplines. The vast majority of pain medicine fellows embark on private practice in an office-based setting after completion of their training. Other disciplines, particularly anesthesiology, which is the primary specialty for the majority of pain medicine fellows, remain mostly hospital-based, and their "business model" is thus different from the model of most pain management practices. Understanding the compensation systems, resource management, and practice models that usually differ from the field in which the trainee completed his or her residency is critical before beginning independent practice.

The ACGME clearly defines minimum standards for procedural and clinical encounters needed to complete a fellowship in pain medicine for accreditation. However, business and practice management education standards are not as clearly defined but are a component of the expected pain management curriculum. Therefore, it is reasonable to assume that there is a high degree of variability in the education areas of business and practice management. The goal of this investigation was to assess how pain medicine fellows are educated in business and practice management and if the hypothesized gap in their expectations and experience in this element of their education does in fact exist. While the one-year model for pain medicine fellowship training after the completion of a core residency is a short time for both clinical and practice management skill development, the latter has clear importance as the trainee transitions into independent practice.

This survey highlights the paucity of practice management and business training among pain medicine fellowship programs, a discipline that sends the extreme majority of trainees into the private sector. Of the responders, $25 \%$ of the fellows stated they receive no formal business training during their fellowship program. It is reasonable to conclude that the addition of this training would help the individual transition into a successful practice. However, the initiation of formal business training has been shown to benefit not only trainees, but also the academic departments providing the training by increasing revenue, as was demonstrated in a neurology department by Waugh et al (5) in 2014.

Of those receiving formal business training in their fellowship, the quantity and source of this training was particularly interesting to the authors. Among the 
Table 1. Survey responses from 56 polled participants of 21 questions, by percent.

\begin{tabular}{|c|c|c|c|c|c|}
\hline Question & $\begin{array}{c}\text { Strongly } \\
\text { Agree (\%) }\end{array}$ & Agree (\%) & Neutral (\%) & Disagree (\%) & $\begin{array}{c}\text { Strongly } \\
\text { Disagree (\%) }\end{array}$ \\
\hline $\begin{array}{l}\text { Would you like to receive more education on } \\
\text { billing documentation/compliance? }\end{array}$ & 46.4 & 46.4 & 3.6 & 3.6 & 0 \\
\hline $\begin{array}{l}\text { Would you like to receive more education on } \\
\text { charges/revenue? }\end{array}$ & 50.0 & 44.6 & 3.6 & 1.8 & 0.0 \\
\hline $\begin{array}{l}\text { Would you like to receive more education on } \\
\text { physician vs. facility revenue? }\end{array}$ & 41.1 & 53.6 & 3.6 & 1.8 & 0.0 \\
\hline $\begin{array}{l}\text { Would you like to receive more education on } \\
\text { precertification/authorization? }\end{array}$ & 28.6 & 58.9 & 8.9 & 3.6 & 0.0 \\
\hline $\begin{array}{l}\text { Would you like to receive more education on } \\
\text { monthly financial reports for practice? }\end{array}$ & 39.3 & 51.8 & 8.9 & 0.0 & 0.0 \\
\hline $\begin{array}{l}\text { Would you like to receive more education on } \\
\text { contracts with payers? }\end{array}$ & 46.4 & 48.2 & 5.4 & 0.0 & 0.0 \\
\hline $\begin{array}{l}\text { Would you like to receive more education on } \\
\text { employee contracts? }\end{array}$ & 48.2 & 41.1 & 7.1 & 3.6 & 0.0 \\
\hline $\begin{array}{l}\text { Would you like to receive more education on } \\
\text { human resource topics (as the employer)? }\end{array}$ & 30.4 & 44.6 & 25.0 & 0.0 & 0.0 \\
\hline $\begin{array}{l}\text { Would you like to receive more education on job } \\
\text { search (CV writing, interviewing)? }\end{array}$ & 23.2 & 33.9 & 26.8 & 14.3 & 1.8 \\
\hline $\begin{array}{l}\text { Would you like to receive more education on } \\
\text { future healthcare options (e.g., Accountable Care } \\
\text { Organizations)? }\end{array}$ & 30.4 & 58.9 & 10.7 & 0.0 & 0.0 \\
\hline $\begin{array}{l}\text { Do you receive education on billing } \\
\text { documentation/compliance? }\end{array}$ & 8.9 & 58.9 & 16.1 & 14.3 & 1.8 \\
\hline Do you receive education on charges/revenue? & 1.8 & 35.7 & 25.0 & 25.0 & 1.8 \\
\hline $\begin{array}{l}\text { Do you receive education on physician vs. facility } \\
\text { revenue? }\end{array}$ & 5.4 & 17.9 & 28.6 & 32.1 & 16.1 \\
\hline $\begin{array}{l}\text { Do you receive education on precertification/ } \\
\text { authorization? }\end{array}$ & 5.4 & 33.9 & 30.4 & 21.4 & 8.9 \\
\hline $\begin{array}{l}\text { Do you receive education on monthly financial } \\
\text { reports for practice? }\end{array}$ & 1.8 & 10.7 & 23.2 & 30.4 & 33.9 \\
\hline $\begin{array}{l}\text { Do you receive education on contracts with } \\
\text { payers? }\end{array}$ & 1.8 & 14.3 & 23.2 & 26.8 & 33.9 \\
\hline Do you receive education on employee contracts? & 1.8 & 26.8 & 16.1 & 28.6 & 25.0 \\
\hline $\begin{array}{l}\text { Do you receive education on human resource } \\
\text { topics (as the employer)? }\end{array}$ & 1.8 & 14.3 & 21.4 & 33.9 & 29.6 \\
\hline $\begin{array}{l}\text { Do you receive education on job search (CV } \\
\text { writing, interviewing)? }\end{array}$ & 1.8 & 32.1 & 28.6 & 23.2 & 14.3 \\
\hline \multirow[t]{2}{*}{$\begin{array}{l}\text { Do you receive education on future healthcare } \\
\text { options (e.g., Accountable Care Organizations)? }\end{array}$} & 1.8 & 19.6 & 26.8 & 33.9 & 17.9 \\
\hline & $\begin{array}{l}\text { Fellowship } \\
\text { Program }\end{array}$ & $\begin{array}{l}\text { Companies/ } \\
\text { Industry }\end{array}$ & & & \\
\hline $\begin{array}{l}\text { Do you receive more practice management } \\
\text { education during "Instruction Courses for Pain } \\
\text { Treatment Devices from Companies" or more in } \\
\text { your Fellowship Program? }\end{array}$ & 26.8 & 71.4 & & & \\
\hline
\end{tabular}

responders indicating that they did receive some sort of practice management training, $64 \%$ of those stated it was only between one and 4 hours throughout the entire fellowship year. While clearly not as important as developing clinical and procedural competency, the disproportionately low amount of business education 
can and should be increased. Also, an astonishing $71 \%$ of these same responders indicated they receive more practice management training from industry-sponsored instructional pain treatment device courses - courses that are not mandated or supported by the ACGME. There are also many opportunities for education in this area on the national societal level. Although the information provided by both industry and professional societies may indeed have value, the lack of supervision or standards allowing for bias is notable. Most trainees receive a very small amount of practice management training during their fellowship and the majority of this education comes from industry-supported courses, not from the ACGME-directed core fellowship program itself.

\section{Strengths and Limitations}

This study represents a unique, first survey of pain medicine fellowship program directors and fellows addressing practice management education within a training program and our study has limitations, as we discuss in the following paragraph.

Seventy percent of the program directors we contacted responded to our survey. Although this is not representative of every ACGME-approved pain medicine fellowship program and the 56 fellows who responded represent a number that is clearly below that of all fellows in training (an estimated 386 fellows in the year the survey was taken) and it is possible that more than one fellow per program responded, as we did not separate out programs for confidentiality reasons, the results can be extrapolated to offer an overall view of the stage of business education in pain medicine. Actually, our survey has a similar response rate as surveys conducted in other fellowship disciplines. The survey conducted by Lansdown of regional anesthesia program directors in 2013 had a response rate of $66 \%$ (1). Ideally, a higher responder rate would provide greater power and scope. However, this is the first survey of its kind, and a starting point to address this topic. It is clear that most programs provide some practice management and business training, but the topics covered vary significantly. This is not unique to practice management training among pain medicine fellowship programs, as other surveys have shown great variation even among clinical training in different post-graduate training programs (6). Also, it is not unique among training programs that resource, practice, and business training is limited compared to other aspects of systems-based clinical practice (7).

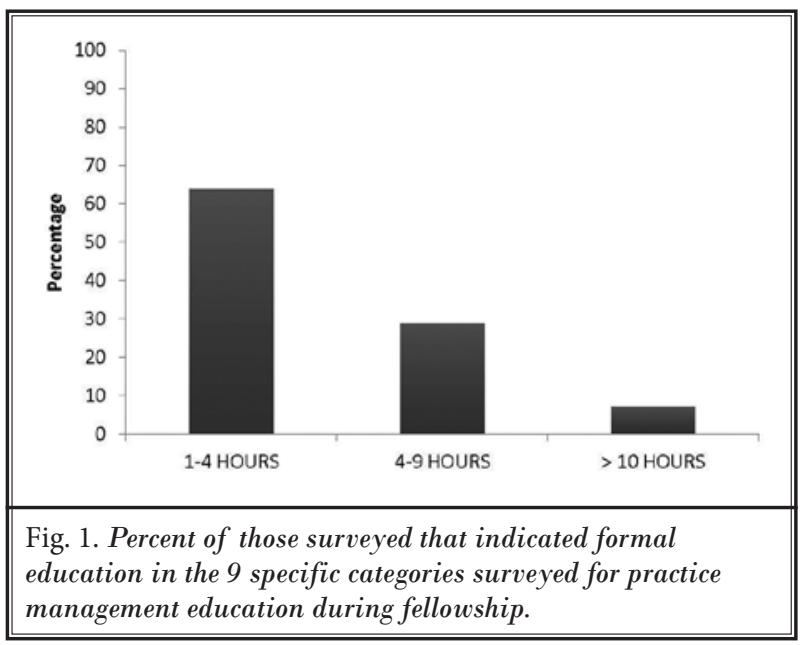

\section{Discussion}

The findings in this survey support a need for enhanced business training during pain fellowship. Given the enormous variation among programs in the quality, quantity, and format of this training, a formal curriculum may assist in creating a more uniform knowledge base in practice management among graduating fellows. We propose the following topics be adopted as standard elements of the core curriculum of pain fellowship training:

- $\quad$ Billing and compliance

- Revenue, physician vs. facility

- Insurance authorization and pre-certification

- Financial reporting and accounting

- Job search

- Contracts with employees

- Contracts with payers

- Human resource

- Future healthcare options

We propose that a formal curriculum for pain medicine fellows be covered twice in the same year, thereby providing more value to the trainee. For example, a lecture concerning billing and compliance may be introduced at the beginning of the year and then revisited later in the year after clinic and procedural experience has created a better understanding and perspective. By covering the aforementioned topics during the pain medicine fellowship, graduates across the country would emerge with an improved and more uniform knowledge base regarding practice management and could more knowledgeably advocate for reputable improvements in reimbursement, pain medicine research, and sociopolitical issues. 


\section{Acknowledgments}

Author Contributions: Drs. Przkora and Abouleish had full access to all the data in the study and take responsibility for the integrity of the data and the accuracy of the data analysis. Drs. Przkora, Abouleish, Brenner, and Mesrobian designed the study protocol. Drs. Antony and McNeil managed the literature searches and summaries of previous related work and wrote the first draft of the manuscript. Drd. Rosenquist, Antony, and McNeil provided revision for intellectual content and final approval of the manuscript.
Role of Sponsor: The financial sponsor of this work had no role in the design and conduct of the study or the collection, management, analysis, and interpretation of the data. The sponsor did not have a role in the preparation or review of the manuscript or the decision to submit. The authors wish to thank Corey Astrom and Adriana Barbat for their assistance in preparation of this manuscript. We also would like to thank the editorial board of Pain Physician for review and criticism in improving the manuscript.

\section{References}

1. Lansdown AK, McHardy PG, Patel SC, Nix CM, McCartney CJ. Survey of international regional anesthesia fellowship directors. Local Reg Anesth 2013; 6:17-24.

2. de Oliveira AF, Lederman HM, Batista NA. Learning on human resources management in the radiology residency program. Radiol Bras 2014; 47:94-98.

3. Hill AD. Improving business IQ in medicine through mentorship and education. J Orthop Trauma 2014; Suppl 9:S9-Sil.

4. Benke JR, Lin SY, Ishman SL. Directed educational training improves coding and billing skills for residents. Int J Pediatr Otorhinolaryngol 2013; 77:399-401.

5. Waugh JL. Education in medical billing benefits both neurology trainees and academic departments. Neurology 2014; 83:1856-1861.
6. Manchikanti L. Current issues in billing and coding in interventional pain medicine. Pain Physician 2000; 3:434-452.

7. Hemmer PR, Karon BS, Hernandez JS, Cuthbert C, Fidler ME, Tazelaar HD. Leadership and management training for residents and fellows: A curriculum for future medical directors. Arch Pathol Lab Med 2007; 131:610-614. 